\title{
Babbel Language Learning Podcasts
}

\author{
https://doi.org/10.3991/ijac.v13i3.17025 \\ Zachary Sporn $\left.{ }^{(}\right)$, Julia Chanter and Daniel Meehan \\ Babbel, Berlin, Germany \\ zsporn@babbel.com
}

\begin{abstract}
Winner of the 2020 IELA E-Learning Award in the category Mobile Learning, Babbel's slate of language learning podcasts provides innovative audio learning experiences, designed and hosted by linguistic experts.
\end{abstract}

Keywords - Mobile-assisted language learning (MALL), second language acquisition, podcasting, audio learning, learning media, how-to

\section{$1 \quad$ Language Learning App Babbel's Pedagogical Method}

Babbel is the world's most financially successful language learning app, with over 10 million subscriptions sold since launching in 2008 and millions of active paying subscribers worldwide. The app is available on iOS, Android and web, with content synced across multiple devices. Babbel's pedagogical method empowers learners to speak a new language in the real world, in real-life situations.

Babbel's core language learning app offers a vast library of lessons in 14 second languages (L2s), all of which are aligned with the language proficiency standards in the Common European Framework of Reference (CEFR; Council of Europe, 2017) and designed to be completed in a relatively short amount of time (roughly 10-15 minutes each). Babbel offers 10,000+ hours of learning content across more than 60,000 lessons, with over 50 hours of video learning content. Babbel courses are designed by language experts with backgrounds in applied linguistics and second language acquisition (SLA) theory.

All 14 languages offered by Babbel feature a core series of "progressive lessons" suitable for beginner and intermediate-level language learners, along with varied modular content targeting specific interests, motivations and skills such as grammar courses and "Business English."

An efficacy study conducted in collaboration with linguists at Michigan State University showed that on average, fewer than 11 hours with the app measurably improved second language speaking skills, as well as explicit grammar and vocabulary knowledge (Loewen et. al., 2020). Independent researchers based at Yale University found that true novices learning Spanish effectively developed their conversational skills: all participants gained some measure of oral proficiency after three months (Van Deusen-Scholl et. al., 2019). An earlier study found that 15 hours of study with Babbel is roughly equivalent to one college semester for novice learners of Spanish (Vesselinov \& Grego, 2016). 


\section{Affordances of L2 Language Learning Podcasts}

Babbel promises to enable users to speak the language like they've always wanted to: the app lessons focus on practical language skills for real-world communication. The goal is for learners to feel competent and confident enough to express themselves using what they've learned, right from the beginning. When considering how we might supplement the app's existing content with other learning experiences, Babbel's product team identified a gap in our offering. We asked ourselves how we could help learners train their listening skills in a flexible way, without a screen, perhaps even while performing another task, like driving or cooking.

We chose podcasts to fill this gap both for educational and business reasons. Contemporary SLA theory acknowledges the crucial role language input plays in language learning, especially in fostering L2 listening comprehension skills needed to function in real-life situations (Dunkel, 1991). Long-form audio can teach listening comprehension, in a low-pressure, user-controlled learning environment; learners have the ability to pause, rewind, and slow the playback speed (Yildrim \& Hoffman, 2010). This plays a useful role in building learners' confidence and facilitating listening comprehension (Gonulal, 2020; Hasan and Tan, 2013).

Recognizing that building up listening skills through extensive listening is a step towards improving conversational skills like pronunciation and speaking (Winitz \& Reed, 1973), we wanted to extend the lesson content to a longform audio format as a suitable and rewarding means of applying language concepts from app lessons, as well as an opportunity for users to hear native and non-native speakers with diverse accents (Sutton-Brady et. al., 2009). Finally, podcasts encourage language learners to take control of their exploration processes; the wide array of language learning podcasts (and vodcasts) allow learners to search for and discover motivational, educational material independently (Hasan and Tan, 2013).

Podcasting is also an established, and flexible medium (Almaqrn \& Alshabeb, 2017), part of many users' existing habits for consuming content on the move that Babbel might piggyback onto. Existing infrastructure for listening, publishing, and gathering user feedback, as well as relatively low production/variable costs, low fixed costs, a low barrier to entry (and exit), made the experiment an attractive and low-risk one. From a content creation standpoint, the team of 150 linguists, instructional designers and language teachers who create Babbel's lessons, along with the newly formed Learning Media team, had the necessary expertise to create engaging and useful audioonly lessons in the form of podcasts. We also anticipated that any audio content produced for podcasts could in the future be repackaged and repurposed, and iterated upon in other ways.

\subsection{First foray into podcasting: learn by doing}

Our primary aim was to create a learning experience that could be enjoyed handsfree, on the go, and supplement and expand the communicative skills covered in the lessons in the app. We also sought to positively reinforce motivation and persistence to use the Babbel app by rewarding learners with a sense of achievement as listening skills 
gained in the app learners enable them to comprehend and engage with longer form listening passages in a podcast.

Our initial foray into podcasting produced a variety of different teaching approaches developed by the in-house linguistic and pedagogical experts at Babbel. They experimented with formats of different lengths, aimed at different levels of linguistic proficiency to cover topics such as idiomatic expressions, pronunciation, and culture.

All six of our current podcasts are hosted by members of Babbel's Didactics team, the language experts who create, edit and optimize the app's language lessons. Most of the hosts are teachers with classroom experience. They seek to create an immediate connection to the learner as well as establish that Babbel's expertise lies in the real people behind their digital courses.

Since launching in 2019, Babbel's language learning podcasts have been downloaded over one million times, cumulatively. Each format we've experimented with so far has found an audience: to date four Babbel podcasts have over one hundred thousand downloads and the rest will very soon cross this threshold.

\section{Challenges and Limitations of Audio-Based L2 Learning}

Throughout the concepting, scripting, and production process, we encountered a variety of challenges and came to understand more clearly the risks we were taking, both from pedagogical and strategic standpoints. Here is a brief overview of some of the challenges:

- Novice language learners need meta-learning support, in other words, guidance on what they should expect when learning a language with podcasts, how to listen actively to native speakers, encouragement and explanations to use podcasting technology (to rewind, to slow playback speed, to replay from the beginning) to shape their experience, and to build their tolerance of ambiguity.

- The audio-only format necessarily precludes visual and textual support that classroom teachers rely on when teaching beginners in order to reduce cognitive load, and to stay in the L2. Listener emails often requested this additional support, especially transcriptions, which complicated our original goal of a screenless, onthe-go offer.

- Addressing the educational challenges for beginner learners by way of support in a learner's native language (L1) dramatically decreases the reach of each podcast to a more limited market, yet beginner-level learners are Babbel's biggest user base.

- To support learners in achieving their speaking goals and act as a steppingstone towards real-life interactions, audio must deliver opportunities to hear natural, authentic language and native speakers in conversation. However, beginners have a limited vocabulary, low exposure to native speakers of their L2, and require simplified sentence structures. We had to find a balance between authentic conversations by native speakers or highly proficient L2 speakers (which could be too challenging) and simplified interactions (which might prove unengaging).

- Creating involving audio for beginners is even more challenging considered in the context of the vibrant array of podcasting and listening options available on Spotify 
or Apple podcasts, where education competes for attention with a vast library of news, entertainment, sports and many other topics.

\section{Validated Approaches and Techniques for Audio-Based Learning}

After launching a variety of different formats, we took some time to reflect on the challenges and work through some solutions. With a cross-functional group, made up of experts in SLA, media, marketing, and instructional design, we brainstormed a variety of methods by which we could create authentic audio for beginners. Key elements and techniques were identified, many of which carry over from the pedagogical method of the Babbel app:

- Content in L2:

- A natural, but slow and clear speaking pace.

- Careful scripting, minimal spontaneity.

- Repetition, at different speeds.

- Use words (cognates) in the L2 that are phonetically similar to their equivalents in the learner's L1.

- Sound design to promote learning: audio cues and sound effects that reduce cognitive load, create context that aids comprehension, creates an immersive, engaging experience.

- Relatable and authentic situations and stories, so listeners learn vocabulary and expressions they might hear in real life.

- Shorter episode target lengths (typically 5-10 minutes).

- One topic per episode, with a clearly communicated structure and targeted learning outcomes.

- Guidance from a relatable host speaking the learner's L1, who provides:

- Additional background information, to connect the cultural context and to make it more relevant.

- Scaffolding, teaching active listening, and suggested techniques for getting the most out of the learning experience, encouraging listeners to experiment.

- Repetition of unfamiliar phrases or expressions.

- Simple grammar explanations illustrated through concrete examples.

\subsection{Applying techniques in the podcast Auf Sprachreise}

We applied the above listed techniques to create the podcast Auf Sprachreise. This podcast was designed for native German speakers learning English at the beginner level. In contrast to many of the explicitly pedagogical podcasts currently produced for L2 learners with low levels of proficiency, Auf Sprachreise features a more content- 
driven format. Each episode features a different native English speaker telling a placebased story accompanied by an immersive soundscape.

Based on survey data and UX research, we know most of the target audience is studying English because they are curious about the world and want to engage with a wide range of cultures and people, not just visit London for a weekend or to put a language qualification on their $\mathrm{CV}$. We also believed by offering a compelling enough audio learning experience that it becomes an end in itself, Babbel subscribers are much more likely to keep coming back to their app lessons, helping to drive retention to our core language app. Therefore, we developed a concept around this podcast's place in an L2 English learner's language journey, as adding texture and color to their experience, while also providing valuable input teaching explicit pronunciation, vocabulary and grammar skills.

Commentary from a native German host is interspersed throughout each story, acting as a kind of friendly, empathetic guide, who translates potentially difficult expressions and explains and calls attention to grammatical concepts. The story can be sliced and diced with enough or as little commentary in whatever language necessary, thus enabling efficient scaling across localization and proficiency level.

We knew that podcast adoption is lower among L1 German speakers than among English speakers. We also observed that our potential listener base of native German speaking L2 English learners is slightly older than the average podcast listener. We saw this, however, as an opportunity to provide real impact for our learners; for $91 \%$ of our listeners this was the first language learning podcast they had ever heard. We had to provide clear and detailed guidance for downloading, accessing and using podcasts; we answered a lot of emails to pleasantly surprised learners explaining that the podcast is free.

\subsection{Successful implementation}

There was a real appetite for content that was both engaging on a personal level and created the kinds of "aha moments" that keep learners coming back for more. Preliminary data show that users who were directed from the Babbel app to relevant podcasts were more likely to start and complete lessons in the app. We saw on average a $10-15 \%$ increase in completion rates of Auf Sprachreise podcast episodes compared to other Babbel podcasts.

Emails from our listeners overwhelmingly point out the value of this podcast being enjoyable as well as enriching from both a language learning and culture perspective. Respondents to a survey ranked each specific technique employed to make engaging stories accessible to beginners highly for adding value to the learning experience, especially the sound design, the contextual and listening guidance, the pace of speech, and the length. Over $90 \%$ of survey respondents said the level was right for them, and that the guidance in German supported their listening skills and improved their understanding. Nearly all respondents had never used a podcast for language learning before, and indicated the in-depth guidance we provided was needed and well received.

While we are still gathering and analyzing the response and effectiveness of the approach of Auf Sprachreise, we are increasingly confident that the application of these 
techniques in this particular concept for this audience was a success. We will continue to investigate creative avenues for authentic audio for beginners, and to understand what differences exist as we bring this approach to different communities of language learners.

\section{$5 \quad$ References}

[1] Almaqrn, R. and Alshabeb, A. (2017. EFL Learners' Attitudes Towards the Proper Pronunciation of English and Podcasts as a Facilitator of Proper Pronunciation. Arab World English Journal (AWEJ), 8, (1). DOI: http://dx.doi.org/10.2139/ssrn.2945902. https://doi.org/10.24093/awej/vol8nol.15

[2] Council of Europe. (2017). Common European framework of reference for languages: Learning, teaching, assessment - Companion volume with new descriptors. Retrieved from https://rm.coe.int/common-european-framework-of-reference-for-languages-learningteaching/168074a4e2. https://doi.org/10.1177/026553220502200310

[3] Dunkel, P. (1991). Listening in the Native and Second/Foreign Language: Toward an Integration of Research and Practice. TESOL Quarterly, 25(3), 431. doi: https://doi.org/10.2307/3586979

[4] Gonulal, T. (2020). Improving listening skills with extensive listening using podcasts and vodcasts. International Journal of Contemporary Educational Research, 7(1), 311-320.DOI: https://doi.org/10.33200/ijcer.685196

[5] Hasan, M. \& Tan, B. H. (2013). Podcast Applications in Language Learning: A Review of Recent Studies. English Language Teaching. 6. https://doi.org/10.5539/elt.v6n2p128

[6] Loewen, S., Isbell, D. R., \& Sporn, Z. (2020). The effectiveness of app-based language instruction for developing receptive linguistic knowledge and oral communicative ability. Foreign Language Annals. doi: https://doi.org/10.1111/flan.12454

[7] Sutton-Brady, C., Scott, K. M., Taylor, L., Carabetta, G., \& Clark, S. (2009). The value of using short-format podcasts to enhance learning and teaching. Alt-J, 17(3), 219-232. doi: https://doi.org/10.1080/09687760903247609

[8] Van Deusen-Scholl, N., Lubrano, M., \& Sporn, Z. (2019, July). Measuring Babbel's Efficacy in Developing Oral Proficiency (Rep.). Retrieved July 8, 2020, from Babbel website: https://press.babbel.com/shared/downloads/studies_research/Measuring-Babbels-Efficacyin-Developing-Oral-Proficiency.pdf

[9] Vesselinov, R., \& Grego, J. (2016, September). The Babbel Efficacy Study (Rep.). Retrieved July 8, 2020, from Compare Language Apps website: http://comparelanguageapps.com/documentation/Babbel2016study.pdf

[10] Winitz, H., \& Reeds, J. A. (1973). Rapid Acquisition of a Foreign Language (German) By the Avoidance of Speaking. IRAL - International Review of Applied Linguistics in Language Teaching, 11(1-4). doi: https://doi.org/10.1515/iral.1973.11.1-4.295

[11] Yildrim, A. H., \& Hoffman, E. (2010). The Power of Podcasts: A Tool to Improve Listening Skills and Empower Learners. In Teaching listening: Voices from the field (pp. 115-132). Alexandria, VA: Teachers of English to Speakers of Other Languages. 


\section{Acknowledgement}

The authors thank Jenny Dorman, Miriam Plieninger and Miriam Weihe for their contributions to this article. We also thank the Didactics team at Babbel who create and host our podcasts: Gianluca Pedrotti, Emanuele Tonetti, Sara Grippo, Charlotte Grandbarbe, Caroline Paboeuf, Laure Cesari, Miriam Weihe, Paula Fernández, David Marín, Héctor Hernández, Catriona Miller, Ted Mentele, Samuel Dowd, Fideniz Ercan, Hannah MacKeith, Tara Musich.

Babbel's Learning Media Team: Frauke Samland, Tom Crewther, Andreas Nielsen, Danny Naldrett, Madeleine Townsend-Clark.

Marketing: Sue Burgstaller.

Babbel's Engineering Team.

\section{Authors}

Zachary Sporn is Senior Communications at Babbel. Among other responsibilities, he coordinates and oversees collaborative research projects, working closely with SLA researchers to evaluate Babbel's lesson content and pedagogical approach. His research interests include mobile-assisted language teaching and learning, educational data mining, voice interfaces and chatbots. Email: zsporn@babbel.com

Julia Chanter is the team lead of the Learning Media team at Babbel, a Canadian education and technology management professional, and long-time podcast enthusiast.

Daniel Meehan is a Learning Media Strategist at Babbel, passionate advocate for digital education and audio fanboy.

Article submitted 2020-07-14. Resubmitted 2020-07-27. Final acceptance 2020-07-29. Final version published as submitted by the authors. 